ENVIRONMENTAL EXPOSURE

\title{
Airway hyperresponsiveness and risk of chest symptoms in an occupational model
}

\author{
K Boutet, J-L Malo, H Ghezzo, D Gautrin
}

See end of article for authors' affiliations

......................

Correspondence to: Dr D Gautrin

Department of Chest

Medicine, Hôpital du

Sacré-Coeur, 5400 Gouin

Blvd West, Montreal,

Canada, $\mathrm{H} 4 \mathrm{~J} 1 \mathrm{C} 5$.

d.gautrin@umontreal.ca

Received 25 November 2005

Accepted 11 July 2006

Published Online First

7 August 2006
Thorax 2007;62:260-264. doi: 10.1136/thx.2005.056333

Background: The clinical outcome of asymptomatic airway hyperresponsiveness (AHR) remains unclear. A study was undertaken to evaluate the incidence of respiratory symptoms in a cohort of asymptomatic subjects with AHR at baseline.

Methods: A 3 year prospective study involving methacholine challenge tests and serially administered questionnaires was undertaken in 769 apprentices exposed to high molecular weight allergens. Analyses were performed on 428 initially asymptomatic subjects.

Results: Thirty eight subjects (8.9\%) were airway hyperresponsive $\left(\mathrm{PC}_{20} \leqslant 8 \mathrm{mg} / \mathrm{ml}\right)$ and asymptomatic at the start of the study. Forty four apprentices $(10.3 \%)$ developed two or more respiratory symptoms unrelated to work, $13(34.2 \%)$ in the AHR group and 31 (7.9\%) in the non-AHR group (risk ratio (RR) 7.88 (95\% Cl 2.53 to 24.55) among subjects with AHR). The RR of developing two or more respiratory symptoms increased as the degree of $\mathrm{PC}_{20}$ decreased with a significant trend $(\mathrm{p}<0.001)$. In a multivariate analysis, AHR (RR $8.33,95 \%$ $\mathrm{Cl} 2.65$ to 26.16 ) and self-reported rhinitis on exposure to pollen through an interaction with a family history of asthma (RR 6.3, 95\% Cl 1.29 to 31.89 ) were associated with the incidence of two or more respiratory symptoms; atopy was not a significant covariate.

Conclusion: AHR in asymptomatic subjects is an important determinant for the development of respiratory symptoms outside the workplace among apprentices exposed to high molecular weight allergens in their training environment.
$\mathrm{R}$ espiratory symptoms such as wheeze, shortness of breath, chest tightness, and cough are not specifically related to asthma. ${ }^{1-3}$ The hallmark of asthma is that these symptoms tend to be variable, intermittent, worse at night, and provoked by triggers including exercise. ${ }^{3}$ On the other hand, respiratory symptoms can also be overlooked by some people with asthma. ${ }^{4}$ These facts contribute to the difficulty in diagnosing asthma from answers to questionnaires only. Functional confirmation of reversible airway obstruction and/or airway hyperresponsiveness (AHR) is also suggested. ${ }^{3}$ The International Consensus Report describes asthma as a "chronic inflammatory disorder of the airway [...] in susceptible individuals, inflammatory symptoms are usually associated with widespread but variable airflow obstruction and an increase in airway response to a variety of stimuli. Obstruction is often reversible either spontaneously or with treatment."

The significance of asymptomatic AHR in the natural history of asthma is currently debated; $57 \%$ of individuals with AHR do not complain of any respiratory symptoms. ${ }^{67}$ Is it a silent state of asthma, an incomplete expression of asthmatic susceptibility, or is it a marker for asthma? During the last decade several studies have addressed this issue, but the findings have often been contradictory and inconclusive, some demonstrating that AHR was a risk factor for developing asthma ${ }^{1289}$ while others showed no such relationship. ${ }^{10-12}$ Demonstrating a "dose-response" relationship between the degree of AHR and the development of respiratory symptoms suggestive of asthma would strongly support the view that asymptomatic AHR is a causal factor. Another characteristic of previous studies is that most of them dealt with the evaluation of either children or teenagers, ${ }^{12}$ a population with a $50 \%$ possibility that asthma symptoms will subside. ${ }^{13}$

One obstacle to evaluating the putative relation between AHR and the development of asthma is the potential role played by concurrent factors that predispose an individual to asthma or that may accompany the disease. Such factors include atopy, ${ }^{2}{ }^{7}$ a family history of asthma, ${ }^{27}$ rhinitis, ${ }^{14}$ smoking, ${ }^{2}{ }^{15}$ forced expiratory volume in 1 second $\left(\mathrm{FEV}_{1}\right),{ }^{7}$ and airway inflammation and remodelling. ${ }^{16}$ All of these have, at various times, been suggested as contributing factors in the development of asthma symptoms.

Identifying characteristic markers in subjects with a predisposition for developing clinical asthma could lead to a better understanding of the natural history of the disease. Moreover, it may also help to identify preventive measures that could in turn contribute to minimising or even eliminating the negative impact of asthma on a patient's quality of life.

As previously suggested, a good model for the study of the natural history of asthma is the natural history of occupational asthma caused by high molecular weight agents. ${ }^{17}{ }^{18}$ The data used here were collected during a previous prospective cohort study of apprentices exposed to proteinic allergens. ${ }^{19}$ The aims of the current study were to describe the development of respiratory symptoms unrelated to the work environment, to establish the presence of a significant dose-response relationship between the degree of baseline AHR and the development of these respiratory symptoms, and to estimate the influence of other baseline characteristics considered as potential risk factors.

\section{METHODS \\ Subjects and design}

A prospective study was conducted between 1993 and 1998 on 769 young adults (15-29 years old) recruited over three consecutive years at the outset of their apprenticeship in a vocational programme (417 in animal health technology, 230 in pastry making, and 122 in dental hygiene technology). The

Abbreviations: AHR, airway hyperresponsiveness; $\mathrm{FEV}_{1}$, forced expiratory volume in 1 second; $F V C$, forced vital capacity; $\mathrm{PC}_{20}$, concentration of methacholine provoking a $20 \%$ fall in $\mathrm{FEV}_{1}$ 
Table 1 Protocol for test administration

\begin{tabular}{lll}
\hline & $\begin{array}{l}\text { Baseline } \\
\text { assessment }\end{array}$ & $\begin{array}{l}\text { Follow up } \\
\text { assessments (up } \\
\text { to three) }\end{array}$ \\
\hline $\begin{array}{l}\text { General symptom questionnaire } \\
\text { Work related symptom }\end{array}$ & $\times$ & $\times$ \\
$\begin{array}{l}\text { questionnaire } \\
\text { Skin tests for allergy }\end{array}$ & $\times$ & $\times$ \\
Spirometry and NSBC test & $\times$ & $\times$ \\
\hline NSBC, non-specific bronchial challenge test. & - \\
\hline
\end{tabular}

recruitment strategy has been described elsewhere. ${ }^{19}$ Briefly, 769 apprentices were recruited from 14 vocational schools in Montreal and other cities in the Province of Quebec to enable us to study the natural history of occupational asthma due to high molecular weight agents specific to certain professions. The cohort members were initially assessed at an average of 1.4 months after their training programme started, and 1-3 reassessments were conducted during the whole programme (18 months for apprentices in pastry making, 32 months for those in dental hygiene, and 32-44 months for those in animal health technology) to evaluate airway responsiveness and immunological status as well as respiratory symptoms related to both the general and work environments (table 1).

The present study focused on lower airway respiratory symptoms unrelated to work. It was performed on a subgroup of 428 subjects who reported no lower airway symptoms at the start of the study, had or did not have upper airway symptoms, and had completed a baseline bronchial challenge $(66.2 \%$ of 647 subjects who were present for at least one follow up); 219 $(33.8 \%)$ apprentices who reported one or more respiratory symptoms at the initial assessment were excluded. The protocol was approved by the Institutional Review Board of the Hôpital du Sacré-Coeur and informed signed consent was obtained from each participant.

\section{Questionnaire}

A respiratory questionnaire derived from the standardised questionnaire of the International Union Against Tuberculosis and Lung Diseases ${ }^{20}$ was administered at the start of the study and at each follow up visit (at 20, 32 and 44 months for the animal health apprentices, at 20 and 32 months for the dental hygiene apprentices, and at 8 and 16 months for the pastry making apprentices). Information was gathered concerning non-work related respiratory symptoms suggestive of asthma (cough, shortness of breath, wheezing, chest tightness, and respiratory complaints occurring under normal circumstances, upon exertion, and upon exposure to cold air, strong odours, smoke or dust). Symptoms were considered to be work related if they occurred at work and disappeared when away from work (weekends and holidays). Subjects were also surveyed for allergy history, smoking habits, family history of asthma, and respiratory and rhinoconjunctivitis symptoms experienced upon contact with pets or pollen.

\section{Skin tests for allergy}

Allergy skin tests (prick method) ${ }^{21}$ with 11 common aeroallergens were administered to each subject: mixed trees, mixed grass and ragweed pollens; Alternaria, Aspergillus, and Hormodendrum; feathers; Dermatophagoides farinae and D pteronyssinus; and cat and dog dander (Omega, Montreal, Canada). Histamine phosphate $(5 \mathrm{mg} / \mathrm{ml})$ was used as a positive control and the diluent (glycerine 50\%) as the negative control. The largest wheal diameter was assessed 10-15 minutes after introduction of the antigen. A positive reaction was defined as a diameter of $\geqslant 3 \mathrm{~mm}$ in the presence of a positive reaction to histamine but without a reaction to the diluent. Allergy skin tests were subsequently performed at each follow up visit. Atopy was defined as a reaction to two or more aeroallergens..$^{22}$

Spirometry and non-specific bronchial challenge tests Spirometric tests were performed using a dry spirometer Collins Survey/l Plus apparatus (W E Collins, Braintree, MA, USA) in accordance with published standards ${ }^{23}$ Methacholine challenge tests were performed with a Wright nebuliser $(0.14 \mathrm{ml} / \mathrm{min}$; Roxon-Medi-Tech Ltd, Montreal, Quebec, Canada) at tidal volume breathing for 2 minutes, exposing the subjects to increasing concentrations of methacholine $(0.03$ to $32 \mathrm{mg} / \mathrm{ml})$ according to the modified European Respiratory Society protocol as previously described..$^{24}$ The provocative concentration causing a $20 \%$ decrease in $\mathrm{FEV}_{1}\left(\mathrm{PC}_{20}\right)$ was interpolated from individual dose-response curves drawn on a semilogarithmic scale. Reference values for $\mathrm{FEV}_{1}$ and forced vital capacity (FVC) were taken from Knudson and co-workers. ${ }^{26} \mathrm{~A}$ $\mathrm{PC}_{20}$ value of $\leqslant 8 \mathrm{mg} / \mathrm{ml}$ was used as the cut off to determine AHR. ${ }^{27}$

\section{Analysis of results}

The outcome was defined as the reporting of two or more lower airway respiratory symptoms at any time during the follow up period. This clinical definition of asthma used was: $\geqslant 2$ respiratory symptoms + reversible bronchoconstriction $\left(\mathrm{FEV}_{1}\right.$ $\leqslant 80 \%$ of predicted value increasing by $\geqslant 12 \%$ and $\geqslant 180 \mathrm{ml}$ after use of a bronchodilator). ${ }^{28}$ Apprentices were considered asymptomatic if they had no lower airway respiratory symptoms at baseline. All analyses were performed on the total study population of 428 asymptomatic subjects.

In order to compare the magnitude of the relationship between $\mathrm{PC}_{20}$ and respiratory symptoms according to increasing severity of AHR, we subdivided the total population into five groups based on airway responsiveness at baseline: group 1: $\mathrm{PC}_{20} \leqslant 4 \mathrm{mg} / \mathrm{ml}(\mathrm{n}=19)$; group 2: $\mathrm{PC}_{20}>4-8.0 \mathrm{mg} / \mathrm{ml}$ $(\mathrm{n}=19)$; group 3: $\mathrm{PC}_{20}>8-16.0 \mathrm{mg} / \mathrm{ml}(\mathrm{n}=36)$; group 4: $\mathrm{PC}_{20}$ $>16-32 \mathrm{mg} / \mathrm{ml}(\mathrm{n}=41)$; group 5: $\mathrm{PC}_{20}>32 \mathrm{mg} / \mathrm{ml}(\mathrm{n}=313)$.

\section{Statistical analysis}

Risk ratios and 95\% confidence intervals (CI) were estimated. The Cochran-Armitage test for trend was performed to assess the increase in risk ratios of respiratory symptoms by

Table 2 Baseline characteristics of asymptomatic subjects classified according to level of airway responsiveness $\left(\mathrm{PC}_{20}\right)$ at start of study

\begin{tabular}{|c|c|c|}
\hline & $\begin{array}{l}\mathrm{PC}_{20} \leqslant 8 \mathrm{mg} / \mathrm{ml} \\
(\mathrm{n}=38)\end{array}$ & $\begin{array}{l}\mathrm{PC}_{20}>8 \mathrm{mg} / \mathrm{ml} \\
(\mathrm{n}=390)\end{array}$ \\
\hline Mean (SD) age (years) & $20.2(4.1)$ & $21.9(7.2)$ \\
\hline Smoking & $4(10.5)$ & $34(8.7)$ \\
\hline Atopy* & $18(47.4)$ & $129(33.1)$ \\
\hline Atopic diathesis & $12(31.6)$ & $68(17.4)$ \\
\hline \multicolumn{3}{|l|}{ Self-reported rhinitis } \\
\hline Non-specific & $20(52.6)$ & $152(39.0)$ \\
\hline To animals & 13 (34.2) & $83(21.3)$ \\
\hline To pollen & 13 (34.2) & 70 (17.9) \\
\hline Ownership of pet at any time & $35(92.1)$ & $358(91.8)$ \\
\hline Family history of asthma & $10(26.3)$ & $69(17.7)$ \\
\hline \multicolumn{3}{|l|}{ Spirometry } \\
\hline Mean (SD) FEV $1 \%$ predicted) & $97.3(8.3)$ & $104.8(11.7)$ \\
\hline $\mathrm{FEV}_{1} \leqslant 80 \%$ predicted & 0 & $8(2.0)$ \\
\hline Mean (SD) FEV $1 / F V C$ & $86.5(5.4)$ & $87.6(5.1)$ \\
\hline
\end{tabular}

Results are presented as number (\%) unless otherwise stated. $\mathrm{PC}_{20}$, concentration of methacholine provoking a $20 \%$ fall in $\mathrm{FEV}_{1} ; \mathrm{FEV}_{1}$, forced expiratory volume in 1 second; FVC, forced vital capacity. *Skin reaction to two or more common aeroallergens.

†Urticaria, eczema or hay fever. 
Table 3 Incident respiratory symptoms during follow up according to the level of airway responsiveness in subjects asymptomatic at baseline

\begin{tabular}{|c|c|c|c|c|}
\hline \multirow{2}{*}{$\begin{array}{l}\text { Level of airway } \\
\text { responsiveness }\left(\mathrm{PC}_{20}\right) \\
(\mathrm{mg} / \mathrm{ml})\end{array}$} & \multirow{2}{*}{$\begin{array}{l}\text { No of } \\
\text { subjects }\end{array}$} & \multicolumn{3}{|c|}{ No of incident respiratory symptoms* } \\
\hline & & 2 & $\geqslant 3$ & $\geqslant 2 \dagger$ \\
\hline$\leqslant 4$ & 19 & 5 & 4 & $9 / 19(47.4 \%)$ \\
\hline $4-8$ & 19 & 4 & 0 & $4 / 19(21.1 \%)$ \\
\hline With AHR & 38 & & & $13(34.2 \%)$ \\
\hline $8-16$ & 36 & 8 & 6 & $14 / 36(38.9 \%)$ \\
\hline $16-32$ & 41 & 5 & 3 & $8 / 41(19.5 \%)$ \\
\hline 32 & 313 & 8 & 1 & $9 / 313(2.9 \%)$ \\
\hline Without AHR & 390 & & & $31 / 390(7.9 \%)$ \\
\hline Overall & 428 & 30 & 14 & $44 / 428(10.3 \%)$ \\
\hline
\end{tabular}

$\mathrm{PC}_{20}$, concentration of methacholine provoking a $20 \%$ fall in $\mathrm{FEV}_{1} ; \mathrm{AHR}$, airway hyperresponsiveness.

*Wheezing, shortness of breath, chest tightness, cough, respiratory complaints upon exertion.

tPercentage of subjects complaining of two or more new respiratory symptoms among those with a given $\mathrm{PC}_{20}$ level who developed new respiratory symptoms.

decreasing $\mathrm{PC}_{20}$ (mutually exclusive $\mathrm{PC}_{20}$ groups as defined above). The joint effect of AHR, smoking, atopy, atopic diathesis (history of physician diagnosed urticaria, eczema, and/or hay fever), self-reported rhinitis (non-specific, to animals or to pollen), pet ownership, family history of asthma, $\mathrm{FEV}_{1}, \mathrm{FEV}_{1} / \mathrm{FVC}$, and training programme (proxy for type of exposure) on the development of respiratory symptoms was assessed by multivariate logistic regression analysis. Analyses were performed using the SPSS software package Version 11.0 for Windows (SPSS, IL, USA). All statistical tests were two sided and a $\mathrm{p}$ value of $\leqslant 0.05$ was considered statistically significant.

\section{RESULTS}

The study population included a greater proportion of women $(85 \%)$ than men, accurately reflecting the student population in these types of vocational programmes in the Province of Quebec, Canada. The baseline characteristics and the prevalence of potential risk factors for developing respiratory symptoms for the total study population are shown in table 2 according to levels of airway responsiveness at the start of the study. Thirty eight subjects $(8.9 \%)$ subjects were found to have AHR $\left(\mathrm{PC}_{20} \leqslant 8 \mathrm{mg} / \mathrm{ml}\right)$ at the commencement of the study (table 2). Almost 9\% were smokers, with an increased proportion among the subjects with AHR (4/38, 10.5\%). Mean spirometric values were within the normal range with only a small proportion of subjects $(\leqslant 2 \%)$ having an $\mathrm{FEV}_{1}$ of $\leqslant 80 \%$. In the population of asymptomatic subjects examined here,

Table 4 Crude risk ratios (RR) of developing two or more respiratory symptoms according to decreasing degree of AHR compared with subjects with $\mathrm{PC}_{20}>32 \mathrm{mg} / \mathrm{ml}$

\begin{tabular}{|c|c|c|}
\hline \multirow[b]{2}{*}{$\begin{array}{l}\text { Airway responsiveness } \\
\left(\mathrm{PC}_{20}\right) \text { threshold values } \\
(\mathrm{mg} / \mathrm{ml})\end{array}$} & \multicolumn{2}{|l|}{ Cumulative† } \\
\hline & $\begin{array}{l}\text { Subjects with } \\
\text { incident respiratory } \\
\text { symptoms } \\
\text { n (\%) }\end{array}$ & $\operatorname{RR}(95 \% \mathrm{Cl})$ \\
\hline $\begin{array}{l}\leqslant 4 \\
\leqslant 8 \\
\leqslant 16 \\
\leqslant 32 \\
>32\end{array}$ & $\begin{array}{l}9(47.4) \\
13(34.2) \\
27(36.5) \\
35(30.4) \\
9(2.9)\end{array}$ & $\begin{array}{l}30.4(9.9 \text { to } 93.0)^{* * *} \\
17.6(6.8 \text { to } 45.1)^{* * *} \\
19.4(8.6 \text { to } 43.8)^{* * *} \\
14.8(6.8 \text { to } 32.0)^{* * *} \\
1\end{array}$ \\
\hline \multicolumn{3}{|c|}{ 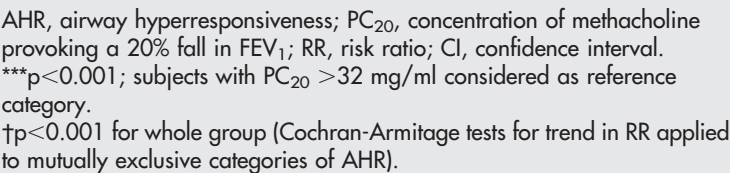 } \\
\hline
\end{tabular}

most baseline characteristics were similar to those published earlier for the entire cohort. ${ }^{19} 22$

Forty four subjects (10.3\%) met our definition of incident respiratory symptoms, having developed two or more non-work related respiratory symptoms during the follow up period; 30/ 255 (4.0\% person-years) had been exposed to laboratory animals, $8 / 99$ (5.4\% person-years) to flour, and 6/74 $(3.0 \%$ person-years) to latex during their apprenticeship (results not shown). Wheezing rarely occurred as a solitary symptom (2/ $428,0.5 \%)$ and was reported by $5.1 \%(22 / 428)$ of the participants when at least two symptoms were reported; respiratory complaint upon exertion was the most frequently reported symptom when at least two symptoms were present $(37 / 428,8.6 \%)$.

Among the asymptomatic apprentices with AHR at the baseline assessment, 34.2\% (13/38) developed two or more respiratory symptoms compared with only $7.9 \%$ (31/390) among those without AHR (table 3). Overall, the cumulative incidence of two or more respiratory symptoms at the end of the follow up period tended to increase with lower baseline $\mathrm{PC}_{20}$ levels, ranging from a low of $2.9 \%(9 / 313)$ in the subgroup with $\mathrm{PC}_{20}>32 \mathrm{mg} / \mathrm{ml}$ to a high of $47.4 \%$ (9/19) in the subgroup with $\mathrm{PC}_{20} \leqslant 4 \mathrm{mg} / \mathrm{ml}$.

Table 5 Crude risk ratios (RR) of developing respiratory symptoms $†$ according to characteristics at baseline in asymptomatic subjects at baseline (univariate analyses)

\begin{tabular}{|c|c|c|}
\hline Characteristics & $\begin{array}{l}\text { No of subjects with } \\
\text { incident respiratory } \\
\text { symptoms }\end{array}$ & $\operatorname{RR}(95 \% \mathrm{Cl})$ \\
\hline $\begin{array}{l}\text { AHR }\left(\mathrm{PC}_{20} \leqslant 8 v\right. \\
>8 \mathrm{mg} / \mathrm{ml})\end{array}$ & 13 & $6.02(2.80 \text { to } 12.92)^{* * *}$ \\
\hline Current smoking & 3 & $0.73(0.21$ to 2.48$)$ \\
\hline Atopy & 23 & $2.38(1.26 \text { to } 4.50)^{*}$ \\
\hline Atopic diathesis§ & 9 & $1.13(0.52$ to 2.46$)$ \\
\hline \multicolumn{3}{|l|}{ Self-reported rhinitis } \\
\hline Non-specific & 31 & $4.11(2.08 \text { to } 8.11)^{* * *}$ \\
\hline To animals & 23 & $4.66(2.45 \text { to } 8.89)^{* * *}$ \\
\hline To pollen & 17 & $3.03(1.56 \text { to } 5.88)^{* *}$ \\
\hline $\begin{array}{l}\text { Ownership of a pet at } \\
\text { any time }\end{array}$ & 41 & $1.24(0.36$ to 4.24$)$ \\
\hline Family history of asthma & 14 & $2.29(1.15 \text { to } 4.56)^{*}$ \\
\hline
\end{tabular}

AHR, airway hyperresponsiveness; $\mathrm{PC}_{20}$, concentration of methacholine provoking a $20 \%$ fall in $\mathrm{FEV}_{1} ; \mathrm{RR}$, risk ratio; $\mathrm{Cl}$, confidence interval. ${ }^{*} \mathrm{p}<0.05 ;{ }^{* *} \mathrm{p}<0.01$; ${ }^{* * *} \mathrm{p}<0.001$.

†At least two of the following symptoms: wheezing, shortness of breath, chest tightness, cough, respiratory complaints upon exertion.

$\ddagger$ Skin reaction to two or more common aeroallergens.

§Urticaria, eczema, or hay fever. 


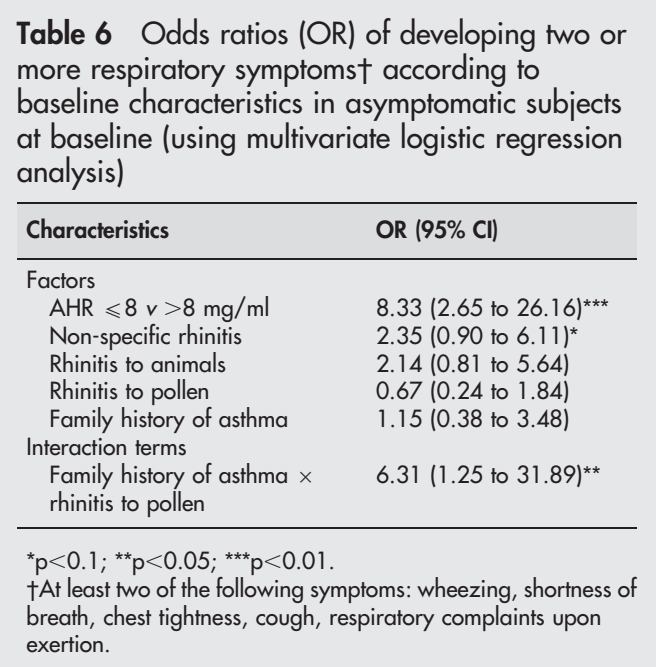

Table 4 presents crude risk ratios of developing two or more respiratory symptoms according to different threshold values of AHR compared with non-measurable AHR. The risk ratio is greatest for subjects with a baseline $\mathrm{PC}_{20}$ of $\leqslant 4 \mathrm{mg} / \mathrm{ml}$ and decreases significantly as the degree of AHR diminishes $(\mathrm{T}=9.06, \mathrm{p}<0.0001$, Cochran-Armitage test for trend in mutually exclusive categories).

The risk ratios and $95 \% \mathrm{CI}$ calculated using $2 \times 2$ contingency tables (univariate analyses) are shown in table 5 . The results show that, among the baseline potential risk factors studied, AHR, atopy, rhinitis symptoms (non-specific, on exposure to animals, and on exposure to pollen), and a family history of asthma were significantly associated with the incidence of respiratory symptoms.

In a multivariate analysis including all these factors and their interaction terms, AHR was significantly associated with the incidence of two or more respiratory symptoms, as was the joint occurrence of a family history of asthma and rhinitis symptoms on exposure to pollen, while the effect of non-specific rhinitis symptoms was of borderline significance (table 6). Training programme had no effect on the association between AHR and the incidence of two or more respiratory symptoms. There was no interaction with the nature of the training programme and thus with the type of work related allergens.

\section{DISCUSSION}

This study showed that, after a $1-4$ year follow up period, asymptomatic subjects with AHR at baseline were at greater risk of developing two or more respiratory symptoms than those without AHR, taking into account other potential risk factors. Self-reported rhinitis on exposure to pollen at baseline in subjects with a family history of asthma was also, to a lesser extent, independently associated with the likelihood of developing respiratory symptoms. An association with non-specific rhinitis was also present, albeit of borderline significance, while atopy did not remain significant in a multivariate model. We reported a $34.2 \%$ incidence for two or more respiratory symptoms among subjects with asymptomatic AHR over a 3 year follow up. This is higher than that reported by other authors. Previously reported figures on the incidence of respiratory symptoms in AHR populations were $14.3 \%$ in a 3 year follow up and 32\% after a 6 year follow up. ${ }^{29}$ This finding is particularly surprising given the requirement of two or more new respiratory symptoms in our study compared with the requirement of only one respiratory symptom used in the other studies. Among participants with non-measurable $\mathrm{PC}_{20}$ at baseline, the incidence of respiratory symptoms was $7.9 \%$ during the 3 year follow up period in our study compared with $0 \%$ in the population followed for a comparable time by Laprise and co-workers; ${ }^{7}$ on the other hand, up to $24 \%$ of subjects without AHR developed respiratory symptoms in the 6 year follow up study conducted by Rasmussen and co-workers. ${ }^{29}$ It must be noted that these previous studies were performed on smaller populations and the documentation of respiratory symptoms was less exhaustive.

When considering different threshold values for airway responsiveness from severe to mild, we saw a significant trend in risk ratios for developing respiratory symptoms indicating a decreased, although not negligible, risk for participants with milder initial $\mathrm{PC}_{20}$.

Our results also highlight the fact that other characteristics of the subject seem to be associated with AHR-namely, rhinitis, atopy, and a family history of asthma. Similar significant associations with AHR have been found in other studies. ${ }^{70}{ }^{31}$ In a multivariate analysis, AHR and the interaction between selfreported rhinitis on exposure to pollen and a family history of asthma remained significantly associated with the incidence of two or more respiratory symptoms, taking into account other potential risk factors. We did not find atopy to be a significant determinant for developing respiratory symptoms when the other factors studied were taken into account. This lack of association, while surprising, has also been reported elsewhere. ${ }^{1}$ The finding that atopy was not a significant determinant for the onset of respiratory symptoms in this population of asymptomatic subjects at baseline may be explained by a lower prevalence of atopy in this group (34\%) compared with the whole cohort $(40.4 \%) .{ }^{19}$ The lower prevalence in the population examined here is probably due to the exclusion of subjects with one or more respiratory symptoms $(\mathrm{n}=219,33.8 \%)$ who are more likely to be atopic.

The mean percentage predicted $\mathrm{FEV}_{1}$ was more than $96 \%$ and the mean $\mathrm{FEV}_{1} / \mathrm{FVC}$ was more than $85 \%$ in all AHR subgroups; the spirometric values showed no correlation with the level of $\mathrm{PC}_{20}$, a finding consistent with those of other investigators. ${ }^{29}$

Another interesting observation is the pattern of occurrence of the different respiratory symptoms. Wheezing is the most frequently reported new symptom when associated with other respiratory symptoms and the least frequent when reported alone, suggesting that it probably appears after other respiratory symptoms. Coughing, on the other hand, appears early; indeed, more than half the subjects who reported coughing did not complain of other respiratory symptoms, which supports previously published findings. ${ }^{32}$ For these reasons, wheezing appears to be of greater relevance to the definition of respiratory symptoms suggestive of asthma. The incidence of non-work related respiratory symptoms in subjects with asymptomatic AHR was high compared with previously published figures. ${ }^{1729}$ The fact that our population was composed of apprentices in occupations involving exposure to high molecular weight agents might have influenced the outcome in subjects with asymptomatic AHR. One could hypothesise that such exposure would favour the expression of asthma in a predisposed individual during the follow up and thus result in an overestimation of the incidence, thereby limiting the generalisation of our findings. Such concern was raised after it was found that, based on skin prick test results, new sensitisation to common aeroallergens was increased at the time of sensitisation to specific allergens present in the workplace in subjects not previously exposed to these specific agents. ${ }^{33}$ In the current analysis we did not study the incidence of work related respiratory symptoms suggestive of occupational asthma. Indeed, the main focus was the development of respiratory symptoms in general. However, in a previously published study we found an incidence of 5.6\% for work related 
respiratory symptoms among the subpopulation of 394 apprentices in animal health technology during a 3 year training programme. ${ }^{34}$ It is not known whether respiratory symptoms suggestive of occupational asthma increase the risk of nonwork related asthma and, if so, to what extent. However, it is interesting to note that the incidence of non-work related respiratory symptoms in subjects with AHR (41.7\%) and those without AHR (8.2\%) was greater than the incidence of work related respiratory symptoms reported earlier. ${ }^{34}$ Estimates of the risk ratios between AHR and non-AHR subjects were studied in the same population of apprentices, minimising the introduction of bias due to occupational exposure. Our findings show that the type of exposure (training programme) did not affect the estimate of the risk ratio for new onset respiratory symptoms due to AHR We hypothesised that the association between AHR and new onset respiratory symptoms reported in this occupational model would be similar in the general population. In this study we were chiefly concerned with the fate of asymptomatic subjects with a measurement of methacholine $\mathrm{PC}_{20}$ of $\leqslant 8 \mathrm{mg} / \mathrm{ml}$ at the commencement of the observation period

In conclusion, in this study population of young apprentices exposed to high molecular weight agents in their training environment, subjects with asymptomatic AHR at baseline were at greater risk of developing lower airway symptoms unrelated to work, taking into account other potential risk factors; subjects with both a family history of asthma and selfreported rhinitis to pollen were also found to be at higher risk. Although the occurrence of respiratory symptoms may be accelerated in this high risk population, we believe that the association with AHR can be applied to the general population. These results suggest that a methacholine challenge test might be considered a relevant test for subjects with measurable $\mathrm{PC}_{20}$, rhinitis, and/or a family history of asthma in order, for example, to recommend reducing their exposure to the environmental factors that contribute to symptomatic asthma or to emphasise the importance of getting an early referral to a physician if they become symptomatic. These findings also raise a relevant clinical question for future research: Would the use of an antiinflammatory preparation be a valuable conduct to prevent the development of clinical asthma in subjects suffering from AHR?

\section{ACKNOWLEDGEMENTS}

The authors thank Mrs J L'Archevêque, Research Technician, Mrs M Magnan, Research Nurse, and Mrs S Boudreau, Research Technician who worked on recruitment, data collection, and database management; and Lori Schubert for reviewing the manuscript.

\section{Authors' affiliations}

K Boutet, J-L Malo, H Ghezzo, D Gautrin, Department of Chest Medicine, Hôpital du Sacré-Coeur, Montreal, Canada

The study was supported by the Medical Research Council Grant No. MT12256 and the Canadian Institutes of Health Research Grant No. MOP53118.

Competing interests: none declared.

\section{REFERENCES}

Zhong NS, Chen RC, Yang MO, et al. Is asymptomatic bronchia hyperresponsiveness an indication of potential asthma? A two-year follow-up of young students with bronchial hyperresponsiveness. Chest 1992;102:1104-9.

2 Rasmussen F, Taylor DR, Flannery EM, et al. Outcome in adulthood of asymptomatic airway hyperresponsiveness in childhood: a longitudinal population study. Pediatr Pulmonol 2002;34:164-71.
3 British Thoracic Society, Scottish Intercollegiate Guidelines Network. British guidelines on the management of asthma. Thorax 2003;58(Suppl I): 1-94.

4 Brand PL, Rijcken B, Schouten JP, et al. Perception of airway obstruction in a random population sample. Relationship to airway hyperresponsiveness in the absence of respiratory symptoms. Am Rev Respir Dis 1992;146:396-401.

5 National Heart Lung and Blood Institute, National Institutes of Health. International consensus report on the diagnosis and treatment of asthma. Eur Respir J 1992;5:601-41.

6 Kolnaar BG, Folgering $\mathrm{H}$, van den Hoogen $\mathrm{HJ}$, et al. Asymptomatic bronchial hyperresponsiveness in adolescents and young adults. Eur Respir J 1997; 10:44-50

7 Laprise C, Boulet LP. Asymptomatic airway hyperresponsiveness: a three-year follow-up. Am J Respir Crit Care Med 1997; 156:403-9.

8 Braman SS, Barrows AA, DeCotiis BA, et al. Airway hyperresponsiveness in allergic rhinitis. A risk factor for asthma. Chest 1987;91:671-4.

9 Gautrin D, Ghezzo H, Malo JL. Rhinoconjunctivitis, bronchial responsiveness, and atopy as determinants for incident non-work-related asthma symptoms in apprentices exposed to high-molecular-weight allergens. Allergy 2003;58:608-15.

10 Josephs LK, Gregg I, Mullee MA, et al. Nonspecific bronchial reactivity and its relationship to the clinical expression of asthma. A longitudinal study. Am Rev Respir Dis 1989; 140:350-7.

11 Chhabra SK, Gaur SN, Khanna AK. Clinical significance of nonspecific bronchial hyperresponsiveness in asthma. Chest 1989:96:596-600.

12 de Gooijer A, Brand PL, Gerritsen J, et al. Changes in respiratory symptoms and airway hyperresponsiveness after 27 years in a population-based sample of school children. Eur Respir J 1993;6:848-54.

13 Gerritsen J. Follow-up studies of asthma from childhood to adulthood. Paediatr Respir Rev 2002;3:184-92.

14 Vignola AM, Chanez P, Godard P, et al. Relationships between rhinitis and asthma. Allergy 1998;53:833-9.

15 Sherman CB, Samet JM. What causes cough and wheeze? Chest 1991;99:1-2

6 Laprise C, Laviolette $M$, Boutet $M$, et al. Asymptomatic airway hyperresponsiveness: relationships with airway inflammation and remodelling Eur Respir J 1999;14:63-73.

17 Malo J. Occupational asthma: a model for environmental asthma? In: Godard P, Bousquet J, Michel F, eds. Advances in allergology and clinical immunology. Carnforth, UK: Parthenon Publishing Group, 1992:391-400.

18 Tarlo SM. Occupational asthma: a valid model for adult asthma? Curr Opin Allergy Clin Immunol 2003;3:91-4.

19 Gautrin D, Infante-Rivard C, Dao TV, et al. Specific lgE-dependent sensitization, atopy, and bronchial hyperresponsiveness in apprentices starting exposure to protein-derived agents. Am J Respir Crit Care Med 1997;155:1841-7.

20 Burney PG, Laitinen LA, Perdrizet S, et al. Validity and repeatability of the IUATLD (1984) Bronchial Symptoms Questionnaire: an international comparison. Eur Respir J 1989;2:940-5.

21 Pepys J. Types of allergic reaction. Clin Allergy 1973;3(Suppl):491-509.

22 Gautrin D, Ghezzo H, Infante-Rivard C, et al. Incidence and determinants of lgEmediated sensitization in apprentices. A prospective study. Am J Respir Crit Care Med 2000; 162:1222-8.

23 American Thoracic Society. Standardization of spirometry. Am J Respir Crit Care Med 1995;152:1107-36

24 Sterk PJ, Fabbri LM, Quanjer PH, et al. Airway responsiveness. Standardized challenge testing with pharmacological, physical and sensitizing stimuli in adults. Report Working Party Standardization of Lung Function Tests, European Community for Steel and Coal. Official Statement of the European Respiratory Society. Eur Respir J Suppl 1993:16:53-83.

25 Troyanov S, Malo JL, Cartier A, et al. Frequency and determinants of exaggerated bronchoconstriction during shortened methacholine challenge tests in epidemiological and clinical set-ups. Eur Respir J 2000;16:9-14.

26 Knudson RJ, Lebowitz MD, Holberg CJ, et al. Changes in the normal maximal expiratory flow-volume curve with growth and aging. Am Rev Respir Dis 1983;127:725-34

27 Cockcroft DW, Killian DN, Mellon JJ, et al. Bronchial reactivity to inhaled histamine: a method and clinical survey. Clin Allergy 1977;7:235-43.

28 Boulet LP, Becker A, Berube D, et al. Canadian Asthma Consensus Report, 1999. Canadian Asthma Consensus Group. CMAJ 1999;161(11 Suppl):S1-61.

29 Rasmussen F, Siersted HC, Lambrechtsen J, et al. Impact of airway lability, atopy, and tobacco smoking on the development of asthma-like symptoms in asymptomatic teenagers. Chest 2000;117:1330-5.

30 Sparrow D, O'Connor GT, Basner RC, et al. Predictors of the new onset of wheezing among middle-aged and older men. The Normative Aging Study. Am Rev Respir Dis 1993;147:367-71.

31 Gibson PG, Mattoli S, Sears MR, et al. Increased peak flow variability in children with asymptomatic hyperresponsiveness. Eur Respir J 1995:8:1731-5.

32 Turcotte H, Boulet LP. Perception of breathlessness during early and late asthmatic responses. Am Rev Respir Dis 1993;148:514-8.

33 Nguyen B, Ghezzo H, Malo JL, et al. Time course of onset of sensitization to common and occupational inhalants in apprentices. J Allergy Clin Immunol 2003;111:807-12.

34 Gautrin D, Ghezzo H, Infante-Rivard C, et al. Natural history of sensitization, symptoms and occupational diseases in apprentices exposed to laboratory animals. Eur Respir J 2001;17:904-8. 